\title{
Diagnosis and antibiotic treatment of acute otitis media: report from International Primary Care Network
}

\author{
Jack Froom, Larry Culpepper, Paul Grob, Aad Bartelds, Peter Bowers, Charles Bridges-W'ebb, \\ Inese Grava-Gubins, Larry Green, Jacqueline Lion, Bertino Somaini, A Stroobant, Rae West, \\ Yair Yodfat
}

\begin{abstract}
Study objective-The relation between a history of disorders suggestive of acute otitis media, symptoms, and findings of an examination of the tympanic membrane and doctors" certainty of diagnosis. Also, to examine differences in prescribing habits for acute otitis media among doctors from different countries.
\end{abstract}

Design-Questionnaires were completed by participating doctors for a maximum of 15 consecutive patients presenting with presumed acute otitis media.

Setting-General practices in Australia, Belgium, Great Britain, Israel, The Netherlands, New Zealand, Canada, Switzerland, and the United States.

Patients -3660 Children divided into the three age groups 0-12 months, $13-30$ months, and $\geqslant 31$ months.

Main outcome measures-General practitioners' responses to questions on their diagnostic certainty and resolution of patients' symptoms after two months.

Results - The diagnostic certainty in patients aged $0-12$ months was $58.0 \%$. This increased to $66.0 \%$ in those aged 13-30 months and 73.3\% in those aged $\geqslant 31$ months. In all age groups diagnostic certainty was positively associated with the finding of a tympanic membrane that was discharging pus or bulging. Redness of the membrane and pain were also associated with certainty in patients aged 13-30 months, and a history of decreased hearing or recent upper respiratory infection was positively associated in patients aged $\geqslant 31$ months. The proportion of patients prescribed antibiotics varied greatly among the countries, from $31.2 \%$ in The Netherlands to $\mathbf{9 8 . 2 \%}$ in both Australia and New Zealand, as did the duration of treatment. Patients who did not take antibiotics had a higher rate of recovery than those who did; the rate of recovery did not differ between different types of antibiotic.

Conclusions-Doctors' certainty of diagnosis of acute otitis media was linked to patient's age. Improved criteria or techniques for diagnosing acute otitis media, especially in very young children, need to be developed. Antibiotic treatment did not improve the rate of recovery of patients in this study.

\section{Introduction}

Patients with acute otitis media account for $12 \cdot 4 \%$ of visits to office based paediatricians ${ }^{1}$ and $1 \cdot 7 \%$ of visits to general practitioners, ${ }^{2}$ yet precise criteria for diagnosing the condition are lacking and the opiimal treatment is uncertain. An international panel of experts defined acute otitis media as "the sudden onset and subsequently short duration of a typical, clinically infected form of otitis media characterized oy $\approx$ middle ear infection behind a reddened ear drum." 3 This definition is inadequate for clinical use because redness of the tympanic membrane $2 \cdot n e$ is insufficient for diagnosis and the additional characteristics of middle ear infection are not described. Clinicians do not agree on the criteria for diagnosis: a survey of 165 paediatricians yielded 147 different sets of diagnostic criteria; 18 different sets oi criteria were used in 26 investigations and in 17 studies no criteria for diagnosis were used. ${ }^{4}$

A tympanic membrane that is dri-ining pus or red and bulging in a sick child is substat tial evidence for acute otitis media, but the search for precise clinical criteria may be futile because there is no definitive means of diagnosing the condition. Even the presence of pathogenic organisms in fluid 5 :om the middle ear obtained by myringotomy is an unreliable indicator as over $30 \%$ of specimens from ears of children who have clinically diagnosed aciate otitis media are sterile ${ }^{s}$ Diagnostic criteria are, however, important, because treatment is given even when imprecise criteria ars used.

The treatment of acute otitis media provides additional dilemmas for doctors. Antibiotics have been widely prescribed since their introduction in the late 1940s. Early investigators reported beti,r outcomes when acute otitis media was treated with antibiotics than with a placebo, ${ }^{67}$ but recent studies have failed to show differences. ${ }^{89}$ The optimal duration of administration of antibiotics is also uncertair with two, three, and five day courses being reported as effective as 7-10 day courses..$^{10-13}$ In a recent study van Buchen et al suggested that symptomatic treatment should be given for three or four days and antibiotics or myringotomy, or both, reserved for those who do not respond. ${ }^{14}$

We examined the relatic: between doctors' diagnostic c. tainty and the presence or abser ce of a history of the condition and signs and symptoms, and the range of treatment given to patients who were thought to have acute otitis media.

\section{Patients and methods}

The International Primary Care Network consisis of several national networks of doctors in primary care who collaborate on research and surveillance of health problems in their patients. The crganisation of this study has already been reported. ${ }^{\text {is }}$ Doctors from networks in nine countries (Australia, Belgium, Canada, Great Britain, Israel, The Netherlands, New Zealand, Switzerland, and the United States) were asked to record data or up to 15 consecutive patients with new episodes of acute otitis media. A new enisode was defined as a new infection with or without a history 
of acute otitis media or chronic serous otitis. Only cases reported by doctors who enrolled nine or more patients (average 13.6) were included because follow up data from this group were more complete. ${ }^{15}$

Diagnostic criteria were not given. Instead, doctors answered a prepared list of questions on patients' history as yes, no, or uncertain; symptoms as yes, no, or uncertain (and noted their duration); and findings of an examination of the tympanic membrane as right, left, or both (see table II). In addition to demographic and family data doctors recorded the patient's age at the first episode of otitis media, the number of attacks in the preceding 18 months, the degree of certainty of diagnosis, and whether their behaviour towards the patient was defensive. Investigations and treatment were also recorded. Information on the certainty of diagnosis was lacking for 53 patients, who were excluded from the analyses of diagnosis but included in the analyses of treatment.

A follow up form containing six questions was completed two months after the initial consultation in $84 \%$ of cases by either the patient (in the form of a postal questionnaire) or the doctor (based on telephone contact with the patient or repeat examination). The questions concerned the total number of subsequent visits, follow up examinations by other doctors, receipt of ear tubes, changes in drug treatment since the first visit, subsequent admission to hospital for the condition, and an assessment of recovery (yes, no, uncertain). If patients had not completely recovered the reasons were identified in a checklist as pain, drainage from ear, hearing problem or other; other reasons were given for $188(6.5 \%)$ (continuing disease 95 patients and unrelated disorders 93 ). A two month

TABLE I-Distribution by age, sex, and country of patients included in study of acute otitis media

\begin{tabular}{|c|c|c|c|c|c|c|c|c|c|}
\hline \multirow[b]{2}{*}{ Country } & \multicolumn{2}{|c|}{ 0-12 Months } & \multicolumn{2}{|c|}{ 13-30 Months } & \multicolumn{2}{|c|}{$\geqslant 30$ Months } & \multicolumn{2}{|c|}{$\checkmark$ Total } & \multirow{2}{*}{$\begin{array}{l}\text { Overal } \\
\text { total }\end{array}$} \\
\hline & Male & Female & Male & Female & Male & Female & Male & Female & \\
\hline Australia & 19 & 15 & 38 & 34 & 122 & 121 & 179 & 170 & 349 \\
\hline Belgium & 10 & 20 & 18 & 22 & 107 & 61 & 135 & 103 & 238 \\
\hline Canada & 7 & 6 & 13 & 6 & 15 & 22 & 35 & 34 & 69 \\
\hline Great Britain & 21 & 22 & 40 & 31 & 233 & 202 & 294 & 255 & 549 \\
\hline Israel & 95 & 85 & 104 & 116 & 124 & 127 & 323 & 328 & 651 \\
\hline The Netherlands & 15 & 14 & 39 & 29 & 170 & 170 & 224 & 213 & 437 \\
\hline New Zealand & 51 & 39 & 54 & 46 & 183 & 172 & 288 & 257 & 545 \\
\hline Switzerland & 8 & 7 & 19 & 13 & 144 & 135 & 171 & 155 & 326 \\
\hline United States & 40 & 34 & 62 & 52 & 170 & 138 & 272 & 224 & 496 \\
\hline Total & 266 & 242 & 387 & 349 & 1268 & 1148 & 1921 & 1739 & 3660 \\
\hline Overall total & & 08 & & 736 & & & & & 3660 \\
\hline
\end{tabular}

^Sex of 137 patients was unknown.

TABLE II -Number (percentage) of patients with histories of certain conditions and symptoms of acute otitis media and results of examination of tympanic membrane by age

\begin{tabular}{lrrr}
\hline & $0-12$ Months & $13-30$ Months & $\geqslant 31$ Months \\
\hline History of: & & & \\
Respiratory infection & $384(74 \cdot 4)$ & $613(80 \cdot 1)$ & $1804(71 \cdot 7)$ \\
Acute otitis media & $213(41 \cdot 3)$ & $523(68 \cdot 4)$ & $1278(50 \cdot 8)$ \\
Chronic serous otitis & $41(7 \cdot 9)$ & $150(19 \cdot 6)$ & $697(27 \cdot 7)$ \\
Nasal obstruction & $118(22 \cdot 9)$ & $140(18 \cdot 3)$ & $591(23 \cdot 5)$ \\
Decreased hearing & & $37(4 \cdot 8)$ & $682(27 \cdot 1)$ \\
Allergy & $31(6 \cdot 0)$ & $88(11 \cdot 5)$ & $473(18 \cdot 8)$ \\
Tonsillectomy/adenoidectomy & $2(0 \cdot 4)$ & $8(1 \cdot 0)$ & $400(15 \cdot 9)$ \\
Ear tubes & $9(1 \cdot 7)$ & $19(2 \cdot 5)$ & $214(8 \cdot 5)$ \\
Prophylactic antibiotic & & $18(2 \cdot 3)$ & $70(2 \cdot 8)$ \\
Symptoms: & $237(46 \cdot 0)$ & $457(59 \cdot 7)$ & $2214(88 \cdot 0)$ \\
Pain in ear & $385(73 \cdot 6)$ & $584(76 \cdot 3)$ & $1653(65 \cdot 7)$ \\
Nasal discharge & $363(70 \cdot 4)$ & $547(71 \cdot 5)$ & $1172(46 \cdot 6)$ \\
Fever & $125(24 \cdot 2)$ & $150(19 \cdot 6)$ & $221(8 \cdot 8)$ \\
Diarrhoea/vomiting & $30(5 \cdot 8)$ & $98(12 \cdot 8)$ & $795(31 \cdot 6)$ \\
Sore throat & $11(2 \cdot 1)$ & $42(5 \cdot 5)$ & $956(38 \cdot 0)$ \\
Reduced hearing & $55(10 \cdot 7)$ & $91(11 \cdot 9)$ & $372(14 \cdot 8)$ \\
Ear discharge & & & \\
Tympanic membrane: & $447(86 \cdot 6)$ & $669(87 \cdot 5)$ & $2131(84 \cdot 7)$ \\
Red & $260(50 \cdot 4)$ & $386(50 \cdot 5)$ & $1195(47 \cdot 5)$ \\
Opaque/dull & $184(35 \cdot 7)$ & $282(36 \cdot 9)$ & $876(34 \cdot 8)$ \\
Bulging & $66(12 \cdot 8)$ & $142(18 \cdot 6)$ & $465(18 \cdot 5)$ \\
Fluid behind membrane & $34(6 \cdot 6)$ & $72(9 \cdot 4)$ & $362(14 \cdot 4)$ \\
Retracted & $45(8 \cdot 7)$ & $73(9 \cdot 5)$ & $264(10 \cdot 5)$ \\
Draining pus & $14(2 \cdot 7)$ & $28(3 \cdot 7)$ & $141(5 \cdot 6)$ \\
Perforated & $5(1 \cdot 0)$ & $11(1 \cdot 4)$ & $63(2 \cdot 5)$ \\
Ear tubes & $8(1 \cdot 6)$ & $11(1 \cdot 4)$ & $30(1 \cdot 2)$ \\
Not visualised & & & \\
\hline & & &
\end{tabular}

follow up was chosen because in other studies over $85 \%$ of middle ear effusions had cleared by 60 days after the onset of acute otitis media. ${ }^{16}$

We formed a hypothesis based on previous work, ${ }^{17}$ expected cooperation during ear examination, and ability to obtain symptoms directly from the patient, that age would be associated with the degree of certainty of diagnosis. The association with age was tested with two logistic regression models, which compared patients aged $13-30$ months and $\geqslant 30$ months with those aged 0-12 months. "Country variables" were included to adjust for confounding by country. We also used logistic regression to estimate the independent contribution of history, symptoms, and findings of an examination of the tympanic membrane to certainty of diagnosis for each of the three age groups. If univariant analysis showed a statistical association $(p \leqslant 0 \cdot 10)$ between any of these variables and the certainty of diagnosis that variable was considered a potential independent contributor. The potential independent contributors were used to construct a logistic regression model for each age group. Country variables were forced into each model to adjust for differences between countries. A significance of $p \leqslant 0.005$ was needed for other variables to remain in the logistic regression model. For findings of examination of the tympanic membrane a score of 0 was used if neither membrane was affected, and 1 if one or both sides were affected. In each age group the number of patients studied was sufficient to use logistic regression analyses using maximum likelihood estimations to assess the independent contribution of these potential contributing factors to certainty of diagnosis. The significance of differences in treatment was tested with $\chi^{2}$ analysis. All data were analysed with the statistical analysis system (SAS). The study was conducted from February to November 1986.

\section{Results}

Data on 3797 cases of acute otitis media from the nine participating countries were included in the analyses. Table I shows the age and sex distributions of the patients. Differences in age distributions of patients reported by the doctors in each country reflect differences in family patterns and patterns of general practice within different health care systems. The predominance of boys is consistent with reports of other studies. ${ }^{17-19}$ The diagnosis was recorded as very certain in $2760(72.7 \%)$ cases, somewhat certain in 828 $(21.8 \%)$, somewhat uncertain in $141(3.7 \%)$, and very uncertain in $38(1.8 \%)$. Because of the small numbers in the last two groups cases in which the diagnosis was considered very certain were compared with all the other cases.

Table II shows the distribution of items in the patients' histories, symptoms, and findings of a tympanic membrane examination by age group. Most patients had had an upper respiratory infection within the past week, and past episodes of acute otitis media were also common. Patients usually reported pain, nasal discharge, and fever. For very young children the parents perceived that pain was present. On examination tympanic membranes were usually red and about a third were bulging. Other findings were less common. The membranes were visualised in almost all patients. The number of patients whose tympanic membranes were visualised increased with increasing age and was related to certainty of diagnosis. The frequency of a history of chronic serous otitis, decreased hearing allergy, ear tubes, and tonsillectomy; symptoms of sore throat and reduced hearing; and physical findings of tympanic membrane retractions, perforations, and the presence of ear tubes all increased with age. Fever, nasal discharge, and diarrhoea or 
vomiting were more common in younger children. These relations were all significant $(p \leqslant 0 \cdot 005)$.

Diagnostic certainty increased from $58.0 \%(n=306)$ in patients aged $0-12$ months to $66.0 \%(n=504)$ in those aged $13-30$ months, and to $73 \cdot 3 \%(n=1837)$ in patients aged $>30$ months. This trend was found in all countries. Adjusting for country variables patients aged 13-30 months were $15 \%$ more likely (odds ratio $1 \cdot 15 ; 95 \%$ confidence interval $1 \cdot 1$ to $1 \cdot 3$ ) and those aged $>30$ months were $53 \%$ more likely $(1.53 ; 1.3$ to $1 \cdot 8)$ to have a very certain diagnosis than those aged $\leqslant 12$ months.

Logistic regression was performed to define the relation of variables in the history, symptoms, and findings of examination of the tympanic membrane with diagnostic certainty by univariant analysis (table III). Draining pus and bulging of the tympanic membrane were strongly correlated with certainty of diagnosis in all age groups. In patients aged $\leqslant 12$ months a history of acute otitis media also contributed to diagnostic certainty. A red tympanic membrane and pain in the ear were important in patients aged 13-30 months and $>30$ months; decreased hearing and a history of an upper respiratory infection were also of value. With the exception of tympanic membrane not visualised in those under 1 year $(p \leqslant 0.06)$, no other variable approached entry into the logistic models.

A total of 2982 patients fulfilled the inclusion criteria for analyses relating to antibiotic treatment. The age and sex distributions of this group did not differ significantly from those of the larger group for whom diagnostic analyses were performed (table I). Most patients received antibiotics except in The Netherlands, where only $31 \cdot 2 \% \quad(n=129)$ were given this treatment (table IV). The ampicillin group of antibiotics (ampicillin, amoxycillin, amoxycillin-clavulanate potassium) was prescribed

TABLE III-Results of logistic regression analysis to identify factors that independently predicted certainty of diagnosis of acute otitis media

\begin{tabular}{lrrr}
\hline & $\begin{array}{c}\text { No of } \\
\text { patients }\end{array}$ & $\begin{array}{r}\text { Odds } \\
\text { ratio }\end{array}$ & $\begin{array}{c}95 \% \text { Confidence } \\
\text { interval }\end{array}$ \\
\hline Age 0-12 months: & & & \\
$\quad$ Draining pus & 45 & 6.97 & $19 \cdot 11$ to 2.54 \\
Bulging tympanic membrane & 184 & 1.99 & 3.03 to 1.31 \\
Any past episodes & 213 & 1.61 & 2.41 to 1.08 \\
Age 13-30 months: & 73 & 11.29 & 26.53 to 4.80 \\
Draining pus & 669 & 3.47 & 6.16 to 1.95 \\
Red tympanic membrane & 282 & 2.81 & 4.12 to 1.91 \\
Bulging tympanic membrane & 457 & 1.43 & 2.04 to 1.00 \\
Pain in ear & & & \\
Age $\geqslant 31$ months: & 264 & 4.23 & 6.52 to 2.75 \\
Draining pus & 2131 & 3.02 & 4.03 to 2.27 \\
Red tympanic membrane & 876 & 2.61 & 3.33 to 2.05 \\
Bulging tympanic membrane & 682 & 1.56 & 1.96 to 1.24 \\
History of decreased hearing & 2214 & 1.52 & 2.03 to 1.14 \\
Pain in ear & 1804 & 1.35 & 1.68 to 1.08 \\
Recent respiratory infection & 30 & 0.26 & 0.54 to 0.12 \\
Tympanic membrane not visualised & 30 \\
\hline
\end{tabular}

TABLE IV - Number (percentage) of patients given antibiotics for acute otitis media by country and age

All patients studied Patients prescribed antibiotics

\begin{tabular}{lrr}
\hline Country: & & \\
Australia & 282 & $277(98 \cdot 2)$ \\
Belgium & 195 & $166(85 \cdot 1)$ \\
Great Britain & 409 & $396(96 \cdot 8)$ \\
Israel & 532 & $486(91 \cdot 4)$ \\
The Netherlands & 413 & $129(31 \cdot 2)$ \\
New Zealand & 487 & $478(98 \cdot 2)$ \\
Switzerland & 284 & $259(91 \cdot 2)$ \\
United States & 380 & $372(97 \cdot 9)$ \\
Age (months): & 416 & $377(90 \cdot 6)$ \\
$0-12$ & 615 & $546(88 \cdot 8)$ \\
$13-30$ & 1951 & $1640(84 \cdot 1)$ \\
$\geqslant 31$ & 2982 & $2563(86 \cdot 0)$ \\
\hline Total & & \\
\hline
\end{tabular}

^All patients from Canada were excluded because of insufficient numbers. Patients from other countries were excluded if follow up data were no Patients from other countries were excluded if follow up data were not
available or if they had been referred to another doctor at their initial consultation.
TABLE $\mathrm{v}-$ Number (percentage) of patients prescribed various antibiotics for acute otitis media by country

\begin{tabular}{lccc}
\hline & Ampicillin drugs & Co-trimoxazole & Othert \\
\hline Australia & $178(64 \cdot 3)$ & $69(24 \cdot 9)$ & $30(10 \cdot 8)$ \\
Belgium & $122(73 \cdot 5)$ & $7(4 \cdot 2)$ & $37(22 \cdot 3)$ \\
Great Britain & $302(76 \cdot 3)$ & $26(6 \cdot 6)$ & $68(17 \cdot 2)$ \\
Israel & $336(69 \cdot 1)$ & $108(22 \cdot 2)$ & $42(8 \cdot 6)$ \\
The Netherlands & $118(91 \cdot 5)$ & $3(2 \cdot 3)$ & $8(6 \cdot 2)$ \\
New Zealand & $351(73 \cdot 4)$ & $69(14 \cdot 4)$ & $58(12 \cdot 1)$ \\
Switzerland & $124(47 \cdot 9)$ & $43(16 \cdot 6)$ & $92(35 \cdot 5)$ \\
United States & $274(73 \cdot 7)$ & $51(13 \cdot 7)$ & $47(12 \cdot 6)$ \\
\hline Total & $1805(70 \cdot 4)$ & $376(14 \cdot 7)$ & $382(14 \cdot 9)$ \\
\hline
\end{tabular}

^Ampicillin, amoxycillin, amoxycillin-clavulanate potassium.

†Erythromycin (38\%), penicillin (22\%), cephalosporins (17\%), and others and combinations $(23 \%)$.

TABLE VI-Number (percentage) of patients prescribed antibiotics for different periods according to country and age ${ }^{\star}$

\begin{tabular}{lrrrr}
\hline & \multicolumn{5}{c}{ Duration of treatment (days) } \\
\cline { 2 - 5 } & \multicolumn{1}{c}{5} & $6-7$ & $8-10$ & \multicolumn{1}{c}{ Other } \\
\hline Country: & & & & \\
Australia & $68(25 \cdot 3)$ & $119(44 \cdot 3)$ & $77(28 \cdot 6)$ & $5(1 \cdot 9)$ \\
Belgium & $41(25 \cdot 5)$ & $25(15 \cdot 5)$ & $94(58 \cdot 4)$ & $1(0 \cdot 6)$ \\
Great Britain & $195(50 \cdot 1)$ & $141(36 \cdot 3)$ & $26(6 \cdot 7)$ & $27(6 \cdot 9)$ \\
Israel & $43(9 \cdot 0)$ & $135(28 \cdot 2)$ & $286(59 \cdot 8)$ & $14(2 \cdot 9)$ \\
The Netherlands & $37(30 \cdot 1)$ & $82(66 \cdot 7)$ & $3(2 \cdot 4)$ & 1 \\
New Zealand & $114(24 \cdot 6)$ & $135(29 \cdot 2)$ & $157(33 \cdot 9)$ & $57(12 \cdot 3)$ \\
Switzerland & $65(25 \cdot 3)$ & $103(40 \cdot 1)$ & $75(29 \cdot 2)$ & $14(5 \cdot 4)$ \\
United States & $4(1 \cdot 1)$ & $23(6 \cdot 3)$ & $336(91 \cdot 8)$ & $3(0 \cdot 8)$ \\
Age in months: & & & & \\
$0-12$ & $56(15 \cdot 3)$ & $105(28 \cdot 7)$ & $188(51 \cdot 4)$ & $17(4 \cdot 6)$ \\
13-30 & $95(18 \cdot 0)$ & $137(25 \cdot 9)$ & $268(50 \cdot 8)$ & $28(5 \cdot 3)$ \\
$>31$ & $416(25 \cdot 8)$ & $521(32 \cdot 3)$ & $598(37 \cdot 1)$ & $77(4 \cdot 8)$ \\
\hline Total & $567(22 \cdot 6)$ & $763(30 \cdot 4)$ & $1054(42 \cdot 1)$ & $122(4 \cdot 9)$ \\
\end{tabular}

^Data on duration were missing in 57 cases.

TABLE VII - Number (percentage) of patients who had recovered two months after first visiting their doctor according to treatment given

No of patients who had recovered Significance

$$
\begin{aligned}
& \text { No antibiotic treatment: } \\
& \text { 0-12 Months } \\
& \text { 13-30 Months } \\
& \geqslant 31 \text { Months } \\
& \text { All ages }
\end{aligned}
$$

$34(87 \cdot 2)$
$62(89 \cdot 9)$

$283(91 \cdot 0)$

$379(90 \cdot 5)$

$p=0 \cdot 73$

$302(80 \cdot 1)$

$467(85 \cdot 5)$

$1343(81 \cdot 9)$

$112(82 \cdot 4)$

$1495(82 \cdot 8)$
$302(80 \cdot 3)$

$302(80 \cdot 3)$
$315(82 \cdot 5)$

$476(84 \cdot 0)$

$623(81 \cdot 7)$

$869(82 \cdot 4)$
$97(79 \cdot 5)$

$p$ Values indicate significance of the relation between age, antibiotic prescribed, or duration of treatment and recovery at two month follow up.

most commonly, with co-trimoxazole a distant second (table V). Together these drugs accounted for $85 \%$ of all antibiotic prescriptions. The type of antibiotics prescribed also varied by country: Dutch doctors mostly used the ampicillin group, Australians were the highest users of co-trimoxazole, and the Swiss often prescribed other types of antibiotic.

There were considerable differences between countries in the periods for which antibiotics were prescribed (table VI). Most patients in the United States were prescribed antibiotics for 8-10 days, while five days was most common in Great Britain, and 6-7 days was most common in The Netherlands. Age was inversely correlated with the duration of treatment and was a significant determinant of whether antibiotics were given (table IV), but no significant differences by age were noted in choice of antibiotics. Most patients (or the parents of patients) reported that they had recovered within two months irrespective of treatment or sex (table VII). Outcome was not affected by the 
certainty of the doctors' diagnoses or the degree to which the doctors thought that their behaviour was defensive. Patients not given antibiotics reported a higher rate of recovery than those who received them $(90 \cdot 5 \%$ v $82 \cdot 4 \% ; \mathrm{p} \leqslant 0 \cdot 0001)$.

\section{Discussion}

Despite numerous investigations, precise diagnostic criteria and optimal treatment for acute otitis media remain uncertain and controversial. Not surprisingly, therefore, doctors participating in the study reported a moderate degree of diagnostic uncertainty when evaluating patients with presumed acute otitis media and their choice of antibiotics and the duration of treatment that they prescribed varied widely.

Our results are mostly similar to those reported by others with regard to history, symptoms, and physical findings. We found that $73 \%$ of patients had had a preceding upper respiratory infection; this is higher than rates reported by some worker ${ }^{1820}$ but similar to that reported by Pukander. ${ }^{21}$ The rate of perforation of the tympanic membrane $(4 \cdot 7 \%)$, which increased with increasing age, was similar to the rates found by Pukander $(4 \cdot 6 \%)^{21}$ and Froom et al $(3 \cdot 0 \%)^{17}$ but less than the $12 \%$ reported in an earlier British study. ${ }^{18}$ Comparative rates of signs and symptoms are difficult to interpret because some studies were prospective, others were retrospective, and age specific data were often not given.

We have shown for the first time that age is an important factor in diagnostic certainty. With patients aged $0-12$ months the doctor depends primarily on examination of tympanic membranes or a history of otitis to make a diagnosis. Unfortunately, patients in this age group are the most difficult to examine because of the small diameter of their ear canals, the generally horizontal plane of the tympanic membranes, and lack of cooperation. When tympanic membranes cannot be visualised there are few additional sources of information that can be used to improve diagnostic certainty. As the patients' age increases a history of significant events becomes a useful additional source of information. Only in those aged over 30 months do symptoms other than pain in the ear or discharge become important. The fact that doctors were very certain of their diagnosis in only $58 \%$ of children aged $0-12$ months is disconcerting because this age group has the highest incidence of otitis media. Additional objective methods of diagnosing either middle ear infections or effusion would be welcome.

Tympanometry is more commonly used to assess the state of children with secretory otitis media than of those with acute otitis media. The technique requires a tight air seal and therefore cannot be performed on a child who is moving or crying. Its validity in children aged 7 months or less is disputed, ${ }^{223}$ and some children cannot be tested..$^{24}$ In a study of 103 patients with acute otitis media the predictive accuracy of tympanometry was only $74.5 \%$ and results obtained from acoustic reflective measurements were equally discouraging, with a sensitivity of only $71 \% .^{25}$ Tympanometry was infrequently performed by our group of doctors, and its usefulness for doctors in primary care has not been proved. Surgical puncture of the tympanic membrane could contribute to diagnostic certainty but is unlikely to be popular among doctors in primary care or their patients. Pneumatic otoscopy is an attractive alternative because additional expensive equipment is not required and correlations with tympanometry are good..$^{26}$ There are no reports, however, of doctors in primary care using it to assess acute otitis media, and the tympanic membranes of young infants are less compliant than those of older children. ${ }^{27}$ Few doctors in our study used otoscopy. Doctors in primary care need to maximise the opportunities for visualising the tympanic membrane by ensuring that the child is immobilised, the light source is good, and a range of sizes of ear specula is available. ${ }^{28}$

The multiple variables that influence doctors' choices of treatment are unknown, and we cannot explain the wide variations among the doctors who participated in our study. A Dutch study that reported no difference in outcome among patients treated with antibiotics, myringotomy, antibiotic combined with myringotomy, and placebo may have been partly responsible for the low use of antibiotics by Dutch general practitioners. ${ }^{8}$ Prepackaging of antibiotics into five day aliquots may account for the British doctors prescribing antibiotics for five days. " Similarly, an expert on otitis media in the United States recommends 10 days' treatment and $92 \%$ of doctors in the United States prescribed 10 day courses. Reported recovery in our patients seemed not to be influenced by either the type of antibiotic given or the period for which it was given, except that rates of recovery were better in patients of all age groups who did not receive antibiotics. As most patients received antibiotics (except in The Netherlands) those who did not may have had less severe attacks than those who did. Severity of attack was not graded in this study.

Our data must be interpreted with caution. All the doctors who participated in the study were volunteers, and their behaviour may not be representative of that of other doctors in the countries studied. We have no reason, however, to believe that there were differences between the two groups. The data do not reflect the incidence of otitis media but detail the findings for the sample of patients who sought medical care from these doctors in primary care. The data should therefore not be extrapolated to all people with acute otitis media. As the study was not controlled conclusions about efficacy of either the type or duration of antibiotic treatment cannot be drawn. Similarly, without a definitive standard to define the presence of acute otitis media the validity of the several signs, symptoms, and tests used by our doctors cannot be assessed. Finally, outcomes reported by patients may not agree with their pathological state, although patients who perceive themselves to be ill will seek medical care and self assessments of health have been reported to be similar to objective findings by physicians. ${ }^{29} 30$

We found wide variations in the treatment of acute otitis media by general practitioners. If our data are confirmed by additional randomised controlled studies they have considerable consequences for medical care. For example, over 24.5 million prescriptions for antibiotics were written for patients in the United States with acute otitis media in 1985 (National Center for Health Statistics; data obtained from the national ambulatory medical care survey 1985 in a special report at our request) and a five day course rather than a 10 day one would save more than $\$ 50$ million in prescribing rates based on the most conservative estimate.

This work was supported by the North American Primary Care Research Group and grants from W K Kellogg and Rockefeller Foundations.

1 Cypress BK. Patterns of ambulatory care in pediatrics; the national ambulatory medical care survey, United States, fanuary 1980-December 1981. Washington, DC: Government Printing Office, October 1983. (Vital and Health Statistics. Series 13 (75). Department of Health and Human Science (PHS) 84-1736.)

2 Cypress BK. Patterns of ambulatory care in general and family practice, the national ambulatory medical care survey, United States, January 1980-December 1981. Washington, DC: Government Printing Office, September 1983. (Vital and Health Statistics Series 13 (73). Department of Health and Human Science (PHS) 83-1734.

3 Lim DJ. Recent advances in otitis media with effusion: report of research conference. Ann Otol Rhinol Laryngol 1985; suppl 116:1-32.

4 Hayden GF. Acute suppurative otitis media in children: diversity of clinical diagnostic criteria. Clin Pediatr 1981;20:99-104.

5 Klein JO, Bluestone CD. Acute otitis media. Pediatric Infectious Disease 1982;1:66-73. 
6 Howie VH, Ploussard JH. Efficacy of fixed combination antibiotics versus separate components in otitis media: effectiveness of erythromycin estollate, triple sulfonamide, ampicillin, erythromycin estolate-triple sulfonamide and placebo in 280 patients with acute otitis media under two and one-half years of age. Clin Pediatr 1972;11:205-14.

7 Laxdal OE, Merida J, Trefer-Jones RH. Treatment of acute otitis media: a controlled study of 142 children. Can Med Assoc $\mathcal{F}$ 1970;102:263-8.

8 van Buchen FL, Dunk JHM, Van't Hof MA. Therapy of acute otitis media: myringotomy, antibiotics or neither? A double-blind study in children Lancet 1981 ; ;i: $883-7$

9 Mygind N, Meistrup-Larsen KI, Thomsen J, Thomsen VF, Josefoson K, Sorensen H. Penicillin in acute otitis media: a double-blind placebocontrolled trial Clin Otolarymgol $1981 ; 6: 5-13$.

10 Meistrup-Larsen KI, Sorensen H, Johnsen NJ, Thomsen J, Mygind N, Sederberg-Alsen $\mathrm{J}$. Two vs seven days penicillin treatment for acute otitis media. Acta Otolaryngol 1983;96:99-104.

11 Bain J, Murphy E, Ross F. Acute otitis media: clinical course among children who received a short course of high dose antibiotic. $\mathrm{Br} \mathrm{Med} \mathcal{F}$ 1985;291 $1243-6$

12 de Saintonge DMC, Levine DF, Savage IT, et al. Trial of three day and 10 day courses of amoxycillin in otitis media. $\mathrm{Br}$ Med $\mathcal{F}$ 1982;284:1078-81.

13 Hendricks WA, Kusmiesz H, Shelton S, Nelson JD. Five vs ten days of therapy for acute otitis media. Pediatr Infect Dis f 1988;7:14-23.

14 van Buchen FL, Peeters MF, Van't Hof MA. Acute otitis media: a new treatment strategy. $\mathrm{Br}$ Med f 1985;290:1033-7.

15 Culpepper L, Froom J. The international primary care network: purpose, methods and policies. Fam Med 1988;20:197-201.

16 Schwartz RH, Rodriquez WJ, Grundfast K. Duration of middle ear effusion after acute otitis media. Pediatr Infect Dis $\mathcal{f}$ 1984;3:204-7.

17 Froom J, Mold J, Culpepper L, Boisseau V. The spectrum of otitis media in family practice. $\mathcal{F}$ Fam Pract 1980;10:599-605.
18 Medical Research Council. Acute otitis media in general practice. Lancet 1957;ii:510-4

19 Teele DW, Klein JO, Rosner BA. Epidemiology of otitis media in children. Ann Otol Rhinol Laryngol 1980;suppl 68:5-6.

20 Bain DJG. Acute otitis media in children: diagnostic and therapeutic dilemmas. I Fam Pract 1978;6:259-65.

21 Pukander J. Clinical features of otitis media among children. Acta Otolaryngol 1983;95:117-22

22 Paradise JL, Smith CG, Bluestone CD. Tympanometric detection of middle ear effusion in infants and young children. Pediatrics 1976;58:198-210.

23 Groothuis JR, Sell HW, Wright PF, Thompson JM, Altemeier WA. Otitis media in infancy: tympanometric findings. Pediatrics 1979;63:435-42.

24 Lampe RM, Weir MR, McLeod H, Aspinall K, Artalego L. Tympanometry in acute otitis media: prognostic implications. Am f Dis Child 1981;135:233-5.

25 Schwartz DM, Schwartz RH. Acoustic immittance findings in acute otitis media. Ann Otol Rhinol Laryngol 1980;suppl 68:211-3.

26 Marchant CD, McMillan PM, Shurin PA, et al. Objective diagnosis of otitis media in early infancy by tympanometry and ipsilateral acoustic reflex thresholds. F Pediatr 1986;109:590-5.

27 Gimsing S, Bergholtz LM. Otoscopy compared with tympanometry. f Laryngol Otol 1983;97:587-91.

28 Barriga F, Schwartz RH, Hayden GF. Adequate illumination for otoscopy: variations due to power source, bulb and head and speculum design. Am F Dis Child 1986;140:1237-40.

29 Maddox GL, Douglass EB. Aging and individual differences: a longitudinal analysis of social, psychological and physiological indicators. $\mathcal{F}$ Gerontol 1974;29:555-63.

30 Palmore $\mathrm{E}$, Linkart $\mathrm{C}$. Health and social factors related to life satisfaction. 7 Health Soc Behav 1972;13:68-80.

(Accepted 11 December 1989)

\section{MATERIA NON MEDICA}

\section{"Bleeding host"}

In the sixth century BC, Pythagoras commented on a "bloody" coloration appearing in some foodstuffs. Tradition has it that when Alexander the Great was beseiging Tyre in 332 BC the bread rations of his army occasionally seemed to contain drops of blood. This was taken as a sign that blood would soon flow in the city of Tyre and that Alexander would be victorious. In the Middle Ages the "bleeding host" (that is, "blood" on the communion bread) was sometimes seen. It was believed to be due to the stabbing of the bread that was to be consecrated in the Eucharist - the host - by unbelieving Jews, who were consequently massacred in the cities where this occurred. On other occasions it was taken as miraculous evidence of transubstantiation (being Christ's actual body), as in the AD 1512 fresco by Raphael in the Vatican which depicts the "Miracle at the mass of Bolsena" in 1263-a priest who doubted the miraculous view of the sacrament found the host "bleeding" in his hands.

Modern scientists have shown that the bacterium Serratia marcescens can be responsible for red pigment in decomposing food. Back in 1819 the bacterium - which at that time was thought to be a fungus - was named after an Italian physicist, Serafino Serrati. The Italians wished to honour Serrati as they believed he had invented the first steamboat but thought he had been slighted by Americans, who claimed this distinction. (Actually it was a Scotsman, William Symington, who built the first practical steamboat, the Charlotte Dundas, which sailed on the Forth and Clyde canal in 1802). Marcescens is derived from the Latin word "to decay" as the pigment fades quickly, being sensitive to light. The organism is widespread in nature, where it grows best on moist starchy substances, gelatin, or milk. In mediaeval times the bread for the sacrament was occasionally kept in the church, which in those pre-central heating days was probably cold and damp. In such an environment the bread would be a prime culture medium for $S$ marcescens, hence the "bleeding host," a truly dramatic testament, particularly to an audience not scientifically trained.

Occasionally the organism has caused problems in intensive care unitssepticaemia, endocarditis, meningitis, infection in wounds, and respiratory and urinary infections. It is therefore an important pathogen and in the 1950s and 1960s the Americans used it in germ warfare experiments. The intensity of the red pigment produced ranges from dark red to pale pink, depending on the age of the colony. It usually gets paler when the organism is subcultured and may disappear altogether-less than $10 \%$ of isolates are pigmented. The pigment was called "prodigiosin" because it was regarded as "amazing," "marvellous," "miraculous." It is reputed to have slight antibiotic powers, which are active against anthrax and coccidioidomycosis. The organism itself on the other hand is resistant to many antibiotics.

Serratia marcescens must not be confused with the small, red, one celled algae found in sea water, which will multiply speedily in favourable conditions of light and warmth. Currently this algae is increasing rapidly in the North Sea and shows up on satellite photographs. A similar algae may also have been responsible for the first biblical plague when the Nile turned to "blood" (Exodus vii: 20-25). - JAMES M DUNLOP, director of public health, Hull

\section{Shadow in the mountain}

It was a late November Saturday, a few years ago. Along with some friends I had driven up from Bristol the previous evening to stay at our favourite walkers' "guest cottage" in Snowdonia's Llanberis Pass. This weekend outing had become an annual custom, undertaken for its own pleasure and to store up health and happy memories for the winter months ahead.

This time the Saturday was spent walking and scrambling the length of the Snowdon horseshoe, that magnificent six hour ridge walk which usually starts with the climb up to Crib Goch - the red ridge, for so it looks from a distance when the light is right. A short downward part precedes the ascent to Snowdon-Y Wyddfa-itself. A tricky sharp descent follows, necessitating compass and steady head and feet if the mist is down, and you are once more on the upward path to the twin peaks of Lliwedd.

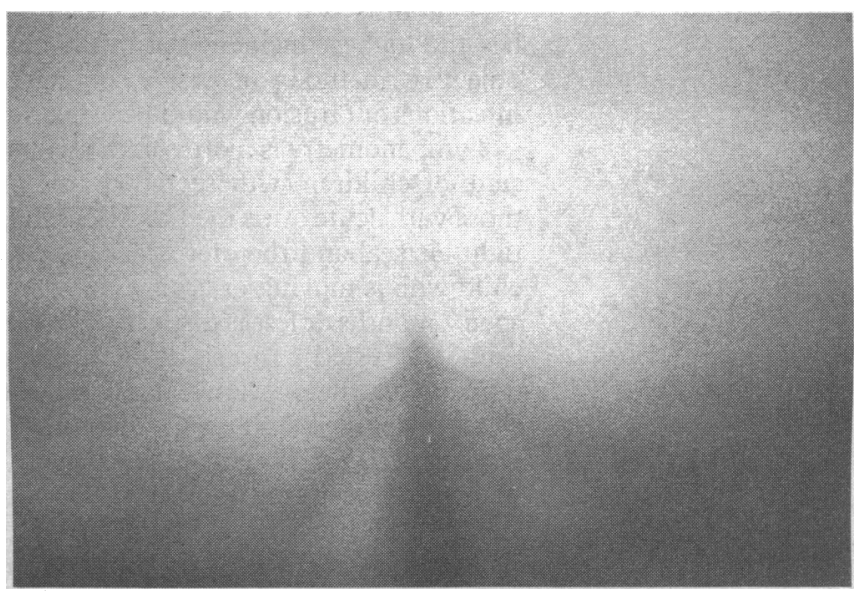

We stopped for a short break on the west peak, but by this time the heavy mist precluded any view. Quite suddenly, a gigantic shadow appeared to the east. It was a Brocken spectre, so named because it was supposedly first described on the German mountains of that name. It is formed by the setting sun throwing a shadow of oneself on the mist, which was just then swirling out of the horseshoe. It is surrounded by a halo, known as a glory. I photographed it and was fortunate to get a good picture. Later enlarged, it now hangs in my surgery, making a nice conversation piece as well as a reminder of that exciting experience.WILLIAM BENNEY, general practitioner, Cheltenham 